\title{
Democratização da educação superior: nexos entre a afirmação da excelência e o desafio do reconhecimento
}

\author{
Democratization of higher education: nexuses between the affirmation of \\ excellence and the challenge of recognition
}

\section{Democratización de la educación superior: vínculos entre la afirmación de excelencia y el desafío del reconocimiento}

\author{
Gregório Durlo Grisa* \\ Célia Elizabete Caregnato
}

\section{Resumo}

As universidades públicas federais brasileiras vivem um importante processo de democratização. Assegurado majoritariamente pela Lei 12.711/2012, ele expõe novas dinâmicas e contradições. Este artigo discute a relação entre excelência acadêmica e o reconhecimento institucional aos novos públicos que ingressam nessas instituições. A base empírica é constituída por oito entrevistas com gestores que ocupam cargos acadêmicos de destaque em uma universidade pública comprometida com a excelência acadêmica, conforme seus documentos oficiais. Para a discussão dos dados, recorremos à ideia de excelência acadêmica e à noção de reconhecimento. Elas apoiam a compreensão de que se está tratando de um universo institucional tensionado entre o objetivo de ser excelente e o de exercer sua função social. Para cumpri-los, a universidade precisa desenvolver formas de lidar com públicos estudantis não tradicionais, os quais crescentemente estão presentes no cotidiano institucional. Concluímos que o processo de democratização em uma instituição que busca afirmação com base na excelência acadêmica necessita reafirmar práticas que ofereçam condições aos novos públicos de estudantes para alcançarem, além do acesso, espaços de prestígio e sucesso acadêmico.

Palavras-chave: Excelência acadêmica. Ações afirmativas. Reconhecimento.

Recebido em 25/06/2019 - Aprovado em 01/10/2019

http://dx.doi.org/10.5335/rep.v27i1.10579

Doutor em Educação e Pós-Doutor em Sociologia pela Universidade Federal do Rio Grande do Sul (Ufrgs, Brasil). Professor do Instituto Federal do Rio Grande do Sul (IFRS, Brasil). ORCID https://orcid.org/0000-0002-1395-7704. E-mail: grisagregorio93@gmail.com

** Doutora em Educação pela Ufrgs. Realizou estágio pós-doutoral na University of Wisconsin (EUA). É professora associada na Universidade Federal do Rio Grande do Sul, membro do corpo permanente do Programa de Pós-Graduação em Educação (Ufrgs, Brasil). ORCID https://orcid.org/0000-0002-9326-590X. E-mail: celia.caregnato@gmail.com 


\section{Abstract}

Brazilian federal public universities are undergoing an important process of democratization. Assured mainly by Law 12.711 / 2012, it exposes new dynamics and contradictions. This article discusses the relationship between academic excellence and institutional recognition for new audiences. The empirical basis consists of eight interviews with managers who hold prominent academic positions in a public university which, according to its official documents, is committed to academic excellence. For the discussion of the data, we turn to the idea of academic excellence and the notion of recognition. They support the understanding that one is dealing with an institutional universe strained between the goal of being excellent and exercising its social function. To fulfill them, the university needs to develop ways of dealing with non-traditional student audiences, which are increasingly present in the daily institutional. We conclude that the process of democratization in an institution that seeks affirmation based on academic excellence needs to reaffirm practices that offer conditions for the new student audiences to achieve, beyond access, spaces of prestige and academic success.

Keywords: Academic excellence. Affirmative action. Recognition.

\section{Resumen}

Las universidades públicas federales brasileñas están experimentando un importante proceso de democratización. Principalmente asegurado por la Ley 12.711 / 2012, el expone nuevas dinámicas y contradicciones. Este artículo analiza la relación entre la excelencia académica y el reconocimiento institucional para las nuevas audiencias que ingresan a estas instituciones. La base empírica consiste en ocho entrevistas con gerentes que ocupan puestos académicos sobresalientes en una universidad pública comprometida con la excelencia académica, de acuerdo con sus documentos oficiales. Para la discusión de los datos, recurrimos a la idea de excelencia académica y la noción de reconocimiento. Apoyan la comprensión de que este es un universo institucional encadenado entre el objetivo de ser excelente y el ejercicio de su función social. Para cumplirlos, la universidad necesita desarrollar formas de tratar con audiencias de estudiantes no tradicionales, que están cada vez más presentes en la vida cotidiana institucional. Concluimos que el proceso de democratización en una institución que busca la afirmación basada en la excelencia académica necesita reafirmar prácticas que ofrezcan condiciones para que las nuevas audiencias de estudiantes alcancen, además del acceso, espacios de prestigio y éxito académico.

Palabras-clave: Excelencia académica. Acciones afirmativas. Reconocimiento

\section{Introdução}

A universidade pública brasileira, em sua rede federal, segue a norma legal que prevê a reserva de vagas para estudantes egressos de escolas públicas, conforme a Lei 12.711/2012, de 29 de agosto de 2012. Isso significa uma transformação expressiva, não apenas no acesso a essas instituições, mas no cotidiano da vida universitária. Diferente de outras realidades nacionais, nas quais as instituições têm prioritariamente funções de pesquisa ou de ensino, no caso da universidade pública brasileira, uma única instituição está sendo chamada a ser competitiva internacionalmente, sendo inclusiva socialmente.

Diante disso, perguntamo-nos: de que forma a universidade concebe-se na sua afirmação pela excelência acadêmica, que remete à obtenção de destaque por meio 
de atividades de pesquisa e de internacionalização, e, ao mesmo tempo, se posiciona frente à necessidade de práticas de reconhecimento relacionadas à inserção e à valorização dos novos segmentos estudantis? O pressuposto é que se a noção de excelência remete à ideia de competitividade internacional, ela também necessita formar o cidadão/profissional com vistas ao desenvolvimento - científico, tecnológico e social - da nação, especialmente no caso de instituições financiadas com recursos públicos. Trata-se da formação de segmentos de elite intelectual, dirigentes para sociedade nacional, e também da oferta de condições para que as novas gerações de jovens tenham desenvolvimento pessoal, profissional e sejam protagonistas de mudanças sociais necessárias.

Simon Marginson (2009) analisou aspectos que determinam a formação dos rankings internacionais das instituições de ensino superior, os quais balizam critérios de financiamento do Banco Mundial para países em desenvolvimento. O autor mostra que há tipos básicos de instituições, voltados para a pesquisa ou para o ensino, como é o caso do sistema norte-americano. Para situar-se nos rankings internacionais é preciso atender à lógica da competitividade a partir de dois movimentos exigidos aos sistemas nacionais. Primeiro, a adaptação ao modelo de universidade com crescente identidade ligada à lógica empresarial. Segundo, o mapeamento do domínio do ensino superior, na forma de uma hierarquia de desempenho institucional, representada pelo resultado da concorrência no mercado. Essas duas políticas de gestão do ensino superior são interdependentes e fazem parte do atual cenário da vida universitária (MARGINSON, 2009). Essa demarcação indica que, para ser uma universidade de excelência acadêmica, a instituição precisa continuar a responder pela atividade de pesquisa num campo de disputas, de eficiência e produtividade.

Para além da constatação de que a universidade forma elites e obedece crescentemente a lógicas exógenas, no caso brasileiro, o sistema necessita democratizar o acesso e as práticas em seu interior para estar habilitado a lidar com novos públicos. Esse desafio se apresenta em um cenário de lutas em que variadas forças disputam reconhecimento por meio de diferentes formas de exercício de poder.

Diferentemente da massificação por meio de títulos desvalorizados (BOURDIEU, 1997) como ocorre num conjunto de vagas criadas em diferentes épocas no Brasil e em outras realidades nacionais, a universidade pública está sendo instigada a garantir qualidade suficiente para o trabalho acadêmico a fim de que os estudantes possam dar saltos em sua formação, compensando, muitas vezes, a trajetória escolar anterior. Nesse contexto, a noção de democratização (SOBRI- 
NHO, 2013) ao invés de massificação (TROW, 2005) do sistema se torna pertinente. Entretanto, caso a instituição se torne incapaz de qualificar seus públicos para participar dos processos de excelência acadêmica, sua capacidade de reconhecimento à diversidade e seu processo de democratização evidenciarão precariedade.

A análise desenvolvida neste artigo tem como base empírica a ótica de dirigentes institucionais de uma universidade pública do sul do Brasil e objetiva problematizar a relação entre a ideia de excelência e competitividade acadêmica e reconhecimento, participação e formação dos novos grupos de estudantes que ingressam na instituição.

Bill Readings (2003) destaca que para entendermos o que é a universidade contemporânea, temos de perguntar o que quer dizer excelência, ou o que não quer dizer. Plenamente inserido no discurso de administradores e gestores universitários, o termo excelência tem origens na área da Ciência da Administração e ganhou ampla circulação no universo acadêmico nos últimos trinta anos ${ }^{1}$.

Ao ter como foco a formação de recursos humanos para o mercado de trabalho e a entrada na disputa científica transnacional, já que a globalização assim a induz, a universidade encontra no termo excelência uma espécie de cobertor semântico. Isso representa uma mudança na função da universidade, em que aquilo que é ensinado e pesquisado interessa menos do que o fato de ser ensinado e pesquisado com excelência (READINGS, 2003).

Diferentemente de uma concepção moderna de universidade, na contemporaneidade, de fato, direcionar as energias do ensino e da pesquisa para a elaboração de uma cultura nacional de referência deixa de ser preponderante na prática acadêmica. As relações entre Estado e universidades perdem força, e estas passam a ser instituições em busca da internacionalização como ferramenta de reconhecimento e financiamento. A legitimidade política que outrora era conferida à universidade pela produção e difusão da cultura nacional, hoje seria alcançada através da produção científica de excelência internacional. Assim como ensina Lyotard (2004), na condição pós-moderna do conhecimento, a performance substitui as meta-narrativas como critério de legitimação.

Esse processo, segundo Readings (2003, p. 24), é a transição vivida pela universidade de uma ideia humboldtiana de cultura para a noção tecno-burocrática de excelência. $\mathrm{O}$ autor salienta que a excelência é o princípio integrador que permite, inclusive, que a "diversidade" (o outro lema dos prospectos da universidade) seja tolerada sem ameaçar a unidade do sistema. A busca da excelência responde bem 
às demandas do capitalismo tecnológico de tornar o conhecimento uma mercadoria e, por carecer de sentido claro, atende a outras demandas sociais no discurso, mas em menor intensidade na prática.

De outra parte, no âmbito das disputas sociais e também do conhecimento filosófico e social, principalmente a partir da segunda metade do século passado, se faz repercutir o uso da noção de reconhecimento. No contexto da relativização de valores universalistas modernos, devido a questões de geopolítica mundial, de afirmação de segmentos antes excluídos ou marginalizados dos processos socais e acadêmicos, o reconhecimento passa a estar no centro de discussões das ciências humanas e sociais (HONNETH, 2003; TAYLOR et al., 1994).

Neste artigo a noção de reconhecimento não é entendida a partir de elementos identitários reivindicados por algum grupo ou segmento social. A compreendemos como componente fundamental da gramática das sociedades contemporâneas (HONNETH, 2003) e inserida na disputa pela definição de uma sociedade mais justa. Nancy Fraser $(2001 ; 2007)$ defende que o conceito de reconhecimento tem de ser vinculado à noção de justiça e analisado como uma questão de status social ao invés do modelo de identidade cultural. O modelo de reconhecimento ligado a identidades priorizaria reivindicações de exclusivismo em detrimento de reivindicações de superação de subordinações injustas. Na perspectiva de Fraser, questões subjetivas dariam espaço para demandas coletivas que implicam valorizar culturas institucionais e status ocupados em seu interior pelos diferentes grupos sociais.

O reconhecimento, no âmbito dos novos públicos da educação superior, cujo ingresso tenha ocorrido com base na reserva de vagas de acordo com a Lei 12.711/2012, precisaria colocar os grupos sociais em paridade para participar da vida acadêmica, seja no âmbito da formação geral, seja no âmbito científico investigativo. Segundo essa abordagem, tanto as condições objetivas, quanto as subjetivas são necessárias para a materialização do reconhecimento. Portanto, o reconhecimento adquire um caráter moral de construção de códigos políticos coletivos no âmbito acadêmico, mais do que a noção ética individual de reconhecimento ou de realização de anseios de personalidade. Com base no material empírico, trataremos da ótica de gestores que ocupam cargos acadêmicos sobre a compreensão do que seja a excelência acadêmica, a função social e cultural da universidade na relação com a perspectiva do reconhecimento dos públicos estudantis não tradicionais ou não herdeiros (BOURDIEU; PASSERON, 2014). 


\section{Metodologia}

Os dados coletados têm origem em um conjunto de oito entrevistas com gestores acadêmicos de uma universidade pública do sul do Brasil, composto da seguinte maneira: seis diretores de unidades acadêmicas e dois membros da administração central, pró-reitores. A escolha dos entrevistados buscou atender à representação das diferentes áreas do conhecimento.

Os diretores de unidade acadêmica ocupam posição estratégica, uma vez que, ao mesmo tempo em que têm contato direto com a administração central e suas políticas, eles também mantêm relação constante com seus pares docentes, com discentes e com o corpo técnico administrativo. Além disso, em geral, são pessoas experientes em suas áreas e na relação com a dinâmica da instituição na qual atuam. Essa realidade confere aos diretores a possibilidade de uma análise global da instituição, o que os torna "informantes-chaves".

Nas entrevistas, indagou-se aos entrevistados suas ideias sobre excelência acadêmica, função social da universidade e cultura acadêmica. As entrevistas foram gravadas com o consentimento de cada um dos entrevistados. Todos encontros ocorreram na universidade por ocasião da pesquisa desenvolvida durante estudos de doutoramento. A figura a seguir codifica e apresenta a composição dos participantes da pesquisa e suas respectivas áreas.

Figura 1 - Entrevistados de acordo com área de conhecimento que atuam

\begin{tabular}{|c|c|}
\hline Entrevistado & Área de atuação \\
\hline E1 & Administração Central \\
E2 & Administração Central \\
E3 & Área da Comunicação \\
E4 & Área das Humanidades \\
E5 & Área das Engenharias \\
E6 & Área da Saúde \\
E7 & Área da Psicologia \\
E8 & Área da Educação \\
\hline
\end{tabular}

Fonte: elaborado pelos autores.

\section{Descrição e análise das entrevistas}

Analisamos o conteúdo das entrevistas organizando-o com base nas três categorias anunciadas, quais sejam, excelência acadêmica, função social da universidade e cultura acadêmica. O objetivo foi abordar o tema em foco a partir de categorias 
que são tradicionais na discussão sobre o papel de uma instituição universitária - função social e cultura acadêmica - bem como pela introdução de uma categoria mais recente - excelência acadêmica - que está presente de maneira intensa no discurso das autoridades e nos documentos oficiais da universidade, como é o caso do Plano de Desenvolvimento Institucional.

\section{Uma universidade de excelência}

Obtivemos um conjunto interessante de representações acerca do estágio de excelência no qual a universidade estaria, bem como sobre o que significa alcançar um nível maior de excelência. Quase todas as respostas valorizaram o tripé que compõe as atividades fundamentais da universidade (ensino, pesquisa e extensão) e que deve ser trabalhado de forma indissociável, segundo a Constituição Brasileira de 1988. Mesmo assim há perspectivas variadas sobre o que seja excelência na universidade.

No entender do gestor E3, uma universidade de excelência é:

Uma universidade que tenha uma grande inserção internacional, que faça parcerias com outros países, que nossos alunos possam fazer cursos fora e voltar e ter várias possibilidades de intercâmbios com outros países, que seus pesquisadores tenham em sua maioria bolsa de produtividade, que consigam produzir e alcançar essas metas de bolsas de produtividade de pesquisa (E3).

Há tanto nas palavras de E3, como de E6 uma dimensão de amplitude espacial, produtividade e medição. E6 avalia que excelência "quer dizer tu publicar, saber se as pessoas leem, quer dizer ser referência para as pessoas, [uma vez que há] medidas que podem ser feitas das publicações, índices de impacto". Nota-se aqui visão cunhada pela interpretação segundo a qual o que legitima a qualidade das universidades é sua capacidade de se internacionalizar e sua produtividade de pesquisa reconhecida pelos órgãos reguladores. $\mathrm{O}$ discurso da excelência, nesse caso, parece dar legitimidade à implantação de um modelo tecnocrata de universidade que tende a substituir o modelo universitário humboldtiano de pesquisa e cultural, convergindo assim com a interpretação de Readings (2003).

E5 afirma:

Acho que, em primeiro lugar, é uma universidade em que as pessoas queiram trabalhar, acho que isso é uma prova de excelência muito grande, quando os alunos almejam estar numa universidade, quando atrai talentos, sejam eles novos alunos e novos docentes e parceiros externos é uma universidade de excelência. E o que precisa para chega lá? Precisa ter competência, bons espaços internos, precisa ter uma boa infraestrutura de pesquisa, precisa ter cursos modernos e bons métodos de ensino. 
Em um exercício estritamente semântico, poderíamos dizer que essa definição de universidade de excelência se assemelha a de uma empresa de excelência, especialmente no que tange a competência, a atração de talentos e a ser moderna. Essa semelhança é fruto da hegemonia de um pensamento de gestão, tanto na esfera pública como na privada, que prioriza aspectos oriundos historicamente da iniciativa privada em escala global. Em outras palavras, ao se lembrar de palavras como competência, destacar necessidade de parcerias com outros setores e cursos "modernos" para uma universidade de excelência, o gestor se utiliza de conceitos chaves da ideologia que sustenta o managerialismo ou a chamada nova gestão pública (HOOD, 1991; POLLITT, 1993). Dentre as características dessa corrente de pensamento, destaca-se a crença de que a ciência da Administração pode ser aplicada a qualquer instituição pública ou privada, isto é, que todos os métodos, medidas e princípios que produzem "bons" resultados no mercado devem ser levados para o setor público onde também teriam êxito.

Destacaremos, agora, respostas que, de alguma maneira, distanciam-se do conceito de excelência criticado por Readings (2003) e que nos convidam a pensar em um conceito de excelência diferente, calcado em outros pressupostos. Na resposta de E7, uma universidade de excelência:

É uma universidade que conseguisse dar conta das três dimensões que ela se propõe, mas que de fato houvesse uma retroalimentação desses três eixos [ensino, pesquisa e extensão]. Na minha opinião, isso ainda é muito precário, essa articulação. Às vezes, a impressão que eu tenho é que são mundos paralelos, o mundo da graduação, o mundo da pós-graduação e o da extensão, para mim o que faltaria para essa excelência nem é tanto o número de artigos científicos, até pode ser, mas deveria ser decorrência de uma outra questão, que é o impacto que essa produção de conhecimento tem junto à comunidade, à sociedade. Portanto, ele vai para a sociedade, produz coisas e volta como forma de conhecimento que pode ser passado para outros atores e entrar nos Rankings internacionais. Que fosse algo que avaliasse o impacto que a universidade tem junto à comunidade, que isso fosse uma coisa mais avaliada internacionalmente do que a produção científica, certamente a universidade teria um outro olhar para extensão, porque ainda não vejo grandes projetos onde as diferentes unidades trabalhassem em projetos comuns, a não ser coisas muito pontuais e nem tanto é extensão (E7).

No caso supracitado, vemos destaque ao compromisso da universidade com as comunidades e a sociedade nacional. Obtivemos outras respostas que entendiam que a prioridade de uma universidade de excelência é sua relação com a realidade local, ou seja, sua capacidade de responder às demandas sociais e econômicas que a realidade próxima apresenta. É possível afirmar que produzir respostas a demandas mais próximas não seria tão somente atender a interesses de determinado setor produtivo ou de determinada empresa que financia a pesquisa, como ocorre 
por meio de programas de transferência de tecnologia referendados como exemplos de excelência, mas incluiria a capacidade, inclusive, de questioná-los (GOERGEN, 2006) e de apresentar alternativas caso isso viesse a beneficiar mais amplamente a sociedade.

E4 afirma que a excelência está relacionada a bons projetos de formação e a um grupo docente altamente qualificado. Ele explica:

O altamente qualificado eu vejo em dois sentidos, isso nós enfrentamos aqui, nos nossos concursos anualmente: existe uma qualificação que é a qualificação científica, no sentido do pesquisador, da produção do conhecimento, do novo, isso, obviamente, é uma questão fundamental, esse é um lado. Mas o outro lado é um docente fortemente inserido na realidade onde ele está, então, isso também é importante para nós, principalmente, no campo da licenciatura, que o cara tem que estar familiarizado com as questões que se colocam de educação na cidade, no estado, no país e no mundo como um todo. Então, esse engajamento, que envolve muito mais do que uma competência técnica na área científica, mas envolve o engajamento político, uma consciência ética, eu diria assim, isso para nós é fundamental (E4).

Identifica-se aqui a valorização do compromisso social dos docentes que não está presente em todas as áreas do conhecimento. Em muitos casos, o sentido da excelência como internacionalização e medição de resultados é o único levado em conta nas seleções feitas nas universidades, mesmo as públicas que têm o concurso público como forma de ingresso. Cabe destacar que o gestor em questão se referiu a licenciaturas, à formação de professores, mostrando com isso sua ligação com a atuação educacional na sociedade.

O gestor reforça sua perspectiva, afirmando que:

Hoje me parece que, muitas vezes, os pesquisadores estão mais preocupados em fazer uma pontuação para se manter dentro dos programas de pós-graduação, para receber financiamento para suas pesquisas, do que ter um engajamento com as grandes questões que são colocadas no mundo, não só para o desenvolvimento do país, mas do ponto de vista global, inclusive. A universidade tem de estar engajada também nessas questões e, às vezes, eu sinto a nossa universidade um pouco distanciada desses aspectos mais prementes, quer dizer, a universidade precisa participar dessas discussões, por exemplo, sobre o ensino médio, o ensino fundamental, o ensino infantil, a educação no campo, a educação de jovens e adultos (E4).

Esse discurso apresenta uma visão de como a rotina no meio acadêmico está criando e valorizando um perfil de pesquisador que não vem conseguindo promover a relação entre o "universal (conhecimentos científicos e tecnológicos) com a diversidade do particular (o ambiente sociocultural)", como sugere Kawasaki (1997). A autora propõe a conjugação das necessidades da realidade local com a globalização econômica em nível mundial. O papel das universidades públicas é ressaltado pela formação de quadros profissionais críticos. O estudo de Kawasaki (1997) aponta 
para a necessidade de as universidades desenvolverem projetos integrados de pesquisa e educação que atendam às áreas de relevância social e econômica.

A interpretação de E4 apresenta uma noção própria de excelência na qual ganha importância a capacidade de inserção das universidades no seu círculo social, nas comunidades que as cercam, não apenas como órgão que legitima um tipo de conhecimento competitivo, mas que convive com atores sociais, principalmente, com aqueles excluídos dos processos de produção do conhecimento. O impacto social que essa inserção da universidade produz representaria a qualidade de uma instituição, segundo esse entrevistado. Essa inserção comunitária, em geral é vista por meio do pilar da extensão universitária, entretanto, para representar uma noção nova de excelência, ela precisaria ser transversal ao ensino, à pesquisa e à extensão.

A interpretação crítica de E1 sobre a noção de excelência vincula o discurso da excelência a alguns grupos de docentes da universidade, que priorizam as relações internacionais e as pesquisas de ponta. Eles entendem essas atividades como de excelência universitária e "não consideram excelentes as respostas a demandas ligadas a sua formação por terminalidade, a demandas ligadas a qual caminho sucessivo faz o egresso, uma série de outros efeitos que [temos a] oferecer [como] formação para o conjunto dos alunos" (E1).

Nas palavras de E8, "uma universidade de excelência é uma universidade vinculada à escola pública, porque somos instituições públicas e, para nós sermos de excelência, nós precisamos de escolas públicas de excelência também". Ainda são muitos os passos para que esse vínculo aconteça de modo mais estruturado, as políticas públicas de formação continuada de docentes que trabalham na rede pública de educação básica estão cada vez mais se apoiando no trabalho das universidades ${ }^{2}$, mas há muito a se avançar nesse sentido.

A responsabilidade pela educação básica não é das universidades, porém, no contexto brasileiro, elas teriam papel importante no sentido de qualificar o sistema educacional público historicamente precário. Como já afirmamos neste artigo, não basta que a universidade cumpra seu papel clássico de formar elites intelectuais e dirigentes, profissionais de ponta, produzir pesquisa básica e aplicada e lidar com a formação cultural para seu público estudantil. Seu desafio transcende essas prerrogativas, a universidade tem funções mais amplas a assumir junto à sociedade.

Para isso, é interessante pensarmos sobre o que diz o gestor E2 que, ao relembrar o mote de campanha para reitor da candidatura vencedora, "Excelência inclusiva", pontua que devemos reinventar muitas coisas no Brasil, e a universidade é uma delas. "É possível a gente ter uma universidade que dê uma formação diferenciada, 
que tenha produção científica e cursos de graduação de alto nível, tendo alunos, que nas condições dadas anteriormente, não entrariam [aqui] de jeito nenhum” (E2).

Segundo o gestor, temos de ressignificar a palavra excelência, dar a ela um conteúdo mais abrangente, não confundir com elitismo como ocorre com alguns setores da universidade. A divisão entre alta e baixa cultura permanece e tem força nas diversas áreas do conhecimento, inclusive naquelas que são ligadas a projetos inovadores de sociedade. Entretanto, também há reprodução de hierarquias e valores elitistas, como mostra o relato a seguir:

Temos a obrigação de criar um quarto modelo de universidade, tem o modelo medieval que chamo de modelo da erudição, o modelo napoleônico que é da formação profissional e o modelo Humboldtiano que é o da pesquisa, o quarto modelo é a gente conseguir juntar esses três porque eu vi professor da universidade, da área de ciências humanas, dizer para os alunos que é inadmissível que aluno universitário goste de pagode, isso é confundir excelência com elitismo. Sim, eu espero que o aluno universitário quando ouça pagode faça uma leitura disso, mas ele pode gostar de escutar pagode, não tem problema nenhum nisso. Infelizmente, existe dentro da universidade, uma confusão muito forte entre elitismo e excelência (E2).

A materialidade do habitus acadêmico (BOURDIEU, 1980) não se constitui apenas de ações autoconscientes, advindas de avaliações e debates acerca de que princípios e valores irão guiar o fazer acadêmico. Pelo contrário, em grande medida, a organização das atividades acadêmicas, suas tradições e formatos, reproduzem uma visão elitista, apoiada em discursos que naturalizam exclusões e evidenciam a falta de análise mais crítica sobre o papel social da universidade.

A noção de excelência presente nos depoimentos apresentados não é única. Ela pode se apresentar por meio da mais alta competitividade internacional da produção do conhecimento, sendo avaliada por parâmetros de produtividade e pela repercussão visível por meio de métricas de avaliação e citações. De outra parte, pode aparecer como compromisso público e social na de qualificação de profissionais para a educação e de desenvolvimento de pesquisas que solucionem problemas concretos da sociedade. Diante disso, cabe verificar de que maneira é compreendida a função social da universidade.

\section{A função social da universidade e a excelência acadêmica}

O objetivo no tratamento deste tema não foi contrapor função social à excelência, como elementos antagônicos, mas instigar que os entrevistados relacionassem essas dimensões de atuação da universidade. Alguns lembraram a extensão 
universitária instantaneamente, pois correlacionam função social com algo como "responsabilidade social corporativa ou empresarial", semelhante a instituições privadas. A extensão universitária cumpriria o papel de promover atividades com comunidades e, com isso, estaria atendida a responsabilidade social da universidade, nos moldes expostos por Ashley (2001, p. 6 e 7):

Responsabilidade social é o compromisso que uma organização deve ter para com a sociedade, expresso por meio de atos e atitudes que a afetem positivamente, de modo amplo, ou a alguma comunidade, de modo específico, agindo proativamente e coerentemente no que tange ao seu papel específico na sociedade e à sua prestação de contas para com ela.

Essa é uma visão genérica conceituada para o mundo dos negócios, mas ela se reflete com força na perspectiva de vários gestores acadêmicos de instituições públicas. Alguns entrevistados não se alongaram na resposta relativa à função social da universidade, apenas fizeram menção à extensão universitária, tratando-as como equivalentes.

O entrevistado E5 propõe pensar função social em dois eixos: o primeiro relacionado ao ensino, seria a função de formar novos talentos, dando oportunidade para todos os segmentos acessarem à universidade. $\mathrm{O}$ segundo eixo estaria ligado à função geradora de conhecimento da universidade, como impulsionadora do desenvolvimento do país.

Então aí se conectam os dois eixos, a universidade tem que ser transformadora, que dê oportunidades ao seu povo, mas ela tem que ser uma universidade que dê competência ao seu mercado privado, que gere empregos para que essas pessoas tenham onde trabalhar, se a gente quer de fato enriquecer o país e dar prosperidade às pessoas. Então o que é preciso? É preciso saber balancear entre as coisas (E5).

Ele sugere, inclusive, que se rompa com o isolamento da universidade e que essa comece a trabalhar em parceria com as escolas desde o ensino médio para atrair talentos, no caso em questão para áreas de engenharias. "Se a universidade tiver de formar em física e matemática, acho que é uma carga muito grande de formação básica e menos formação aplicada que é o que hoje o mercado está nos pedindo", afirma E5. Ele lembra da importância de programas governamentais, para promover uma "transição mais suave" do ensino médio para o superior, como os de popularização da ciência que trabalham com o reforço das exatas, segundo o gestor há muito a se avançar nesse sentido.

Outro caminho tomado para responder à questão sobre função social na relação com a excelência, foi concebê-la como dicotomia. E1 afirma que os setores sociais que fundaram as universidades brasileiras não as prepararam para formar 
sujeitos comprometidos socialmente e nem para que as instituições tivessem protagonismo de induzir mudanças estruturais no país. Pelo contrário, a elite social que criou e frequentou o ensino superior, por quase um século, tinha como prioridade a formação de uma elite intelectual e de profissionais liberais que se perpetuavam nas posições privilegiadas socialmente. Quando convidado a pensar sobre função social e excelência, o gestor afirma:

Acho que é uma dicotomia verdadeira que reproduz dicotomias externas à universidade. E é uma dicotomia também ligada ao fato de que a gente não vem de uma egrégia história, os setores que aparelharam a universidade para que ela servisse às suas demandas não o fizeram em cima de uma história consolidada na qual outras coisas eram feitas e iriam continuar sendo feitas e concorrem para outras funções. [...] Aqui se instalou uma universidade profissionalizante sobre o nada, e essas escolas [profissionais] são fortes até hoje (E1).

Ao afirmar que a dicotomia tem origem fora da universidade, o gestor remete ao sentido de que as disputas da sociedade, de classe, raciais, de gênero e outras, constituem embates também nas universidades. As hegemonias constituídas na sociedade por meio do poder econômico, do racismo e do machismo exercem suas forças nas instituições, mesmo nas que se pretendem o berço do saber e da civilização. Com a democratização das universidades, processo complexo em curso, ampliam-se as contradições entre aqueles que representam os setores que fundaram as universidades para si e os grupos sociais historicamente excluídos que trazem demandas mais ousadas no que tange à atual função social da universidade.

Vivemos uma transição paradigmática acerca do que significa a função social da universidade. Uma visão liberal sobre as relações entre universidade, estado e mercado, tende a ver a universidade atendendo demandas primordialmente de mercado, tanto no que se refere à formação profissional, quanto à produção de pesquisa. Esse tipo de gestão é comum entre instituições de ensino superior privadas que se expandem no mercado em diversos países (MARGINSON, 2009). Com o advento de políticas como as ações afirmativas e a ampliação das vagas públicas, no caso brasileiro, vive-se uma oportunidade histórica de erigir a relação entre universidade e sociedade de modo distinto da tradição elitista da universidade pública e também distinto de tendências mercadológicas internacionais. $\mathrm{O}$ desafio é construir um significado mais plural para o que seja a função social da universidade.

As análises teóricas mais recentes das políticas de reserva de vagas sociais e raciais na universidade brasileiras adotam uma concepção assimilacionista (CAMPOS, FEREZ JÙNIOR, 2014). Isso significa que é ofertada "a equalização de oportunidades sociais e a consequente assimilação de grupos subalternos aos estratos 
superiores da sociedade", sendo que tais políticas tendem a produzir um efeito de inclusão social, mas não necessariamente de construção de pertencimento étnico e cultural (CAMPOS, FEREZ JÙNIOR, 2014). Esse limite se deve ao impacto restrito das políticas afirmativas, bem como à presença restrita de macrocenários de pesquisa e de mudanças epistêmicas substanciais no que tange às práticas de ensino, à pesquisa socioeducacional e a atividades de extensão junto desses grupos sociais.

\section{Cultura acadêmica e extra-acadêmica}

Relativamente à compreensão sobre cultura acadêmica e extra-acadêmica, sua relação e os limites de sua interlocução, questionamos os gestores sobre a capacidade dos atores que fazem a universidade, de reconhecerem os saberes acumulados pelo novo público ingressante, saberes não científicos, modos culturais de manifestação e modos próprios de estudos, diferentes dos públicos tradicionais da universidade.

Há gestores que entendem haver pouco avanço na compreensão do tema, mesmo diante da reserva de vagas para públicos que ingressam com base em escolarização distinta daquela que dominou a universidade até então. Por outro viés, há gestores que destacam haver maior abertura da universidade para experiências e saberes obtidos por meio de uma história cuja presença de lógicas científicas é mais rarefeita. Todos os entrevistados mencionaram as diferenças entre as áreas do conhecimento quanto ao tema em questão.

Como se pode notar abaixo, existe uma clara visão de que os cursos ligados às Ciências Humanas podem oferecer mais receptividade às experiências trazidas pelos estudantes.

Acho que isso depende muito da área, as humanas têm mais sensibilidade para acolher esse tipo de questão (...) para valorizar saberes locais, para não chegar lá colocando uma banca achando que só tu sabe (...) Acho que as humanas têm essa experiência, nas outras áreas isso é mais difícil, na saúde e nas exatas (E7).

Em uma linha mais otimista, E3 entende que a universidade está mais aberta a conhecimentos não científicos do que há alguns anos. Ele usa como exemplos alguns convênios da universidade com a iniciativa privada que financiam o trabalho de comunidades originais, o "da museologia que está recebendo recursos do Santander Cultural para investir nas artesãs da Ilha da Pintada que trabalham com as escamas de peixe", citou o gestor. 
Para além dessa perspectiva mais imediata, de como a universidade pode reconhecer, no seu cotidiano, conhecimentos tradicionais, as entrevistas provocaram reflexões sobre os efeitos dessa "abertura" da universidade, por exemplo, na formação de professores. E5, um dos gestores área de Ciências Exatas, destacou que para os professores mais velhos as mudanças de público que acessam a universidade representam um desafio maior, porque o docente já está acostumado a trabalhar "de certa forma" há mais tempo. Comentou que as Comissões de Graduação de cursos mais novos, com docentes recém-concursados têm uma relação com os discentes bem mais harmônica e sugere que quem organiza os cursos mais tradicionais e antigos deve aprender com essa experiência.

A formação continuada de professores universitários concursados, promovida pela instituição, em modalidade de capacitação e outros cursos, ainda encontra resistências em muitas áreas. A necessidade de renovar metodologias, aprender acerca de aspectos socioculturais da população negra e de baixa renda vem se tornando pauta com as ações afirmativas, mas a execução de formações nesse sentido não é de fácil implementação.

Vamos ter que pensar um ambiente mais complexo, mais tolerante em várias coisas, acho que, para áreas mais duras, vai ser um pouco mais difícil, algum conjunto dos docentes da engenharia ainda tem um modelo de relacionamento com o aluno e uma expectativa da dedicação desse aluno que talvez hoje exclua parte do percentual de alunos que está entrando, vamos ter que tentar transformar isso, acho que é um processo de experiências com responsabilidade, porque a gente não pode ser experimentalista e tentar fazer coisas diferente e prejudicar a formação dos alunos e vai passar por um processo, inclusive, da gente quase que recapacitar os nossos docentes para trabalhar com essa maior diversidade de alunos. Vamos ter que dar novas experiências para os nossos docentes (E5).

Nas palavras do gestor, identificamos a aceitação da necessidade de recapacitar docentes que não sejam familiarizados com a linguagem, as demandas e os modos de vida da população que está ingressando pelas ações afirmativas. Aqui estamos diante de um grande desafio para os gestores universitários responsáveis por planejar e executar tais formações ou capacitações, tendo em vista que, facilmente, pode-se cair em simplificações, reproduções de estereótipos e idealizações desse aluno cotista.

Daí a necessidade de que a formação contemple dimensões como diversidade e o debate acerca do racismo em toda sua complexidade. As universidades têm limites e terminam por cumprir parcialmente ou não cumprir a Lei 10.639, a qual obriga que se trabalhe a cultura africana e afro-brasileira nos cursos de formação de professores e, transversalmente, em todos os cursos da instituição. Nas avaliações 
feitas pelo MEC, para fins de reconhecimento, credenciamento e recredenciamento de cursos da universidade em questão, a aplicação da lei é reiteradamente cobrada.

Um segundo obstáculo relativamente ao aluno que tem ingressado na universidade é a formação no Ensino Médio. Imaginar que aquele jovem paupérrimo, negro, com dificuldades, que perambula no imaginário da classe média, irá usufruir do direito garantido pelas ações afirmativas seria ingenuidade. $\mathrm{O}$ percentual de estudantes negros que finalizam o ensino médio é muito aquém do índice de bran$\cos ^{3}$. A segregação ocorre antes do ensino superior, o público que consegue terminar o ensino médio talvez seja aquele que tenha alguns recursos econômicos na família.

O elemento da formação continuada dos docentes foi sugerido por E1 de maneira peculiar. Ao ouvirmos depoimentos como o de E5, acima, identificamos que algumas áreas, nomeadamente as engenharias, a física, a química, demonstram desconforto quando se trata de reconhecer conhecimentos não científicos, populares ou de senso comum, ou seja, conjunto de saberes simples, pouco elaborados que resultam da experiência de vida e não de investigações científicas. Vejamos a opinião de E1:

Existem áreas nas quais eu não vejo lugar para isso, nem agora nem no futuro, penso especialmente nas engenharias, acho que a noção seminal da engenharia é pós-popular, é diferente da saúde. Fico muito sensibilizada com a legítima inquietação de alguns professores desses campos. Igualmente a física. Existe um limiar de precisão da racionalidade desses atores que é inegociável, a vida humana no sentido estético e de projeto social é intrinsecamente variável, a sua potência passa pela variabilidade e nesses campos a precisão é a noção seminal, a produção do igual dali para a frente $(\mathrm{E} 1)$.

Quando fala em noção seminal da área, o gestor assevera que tal área surgiu em função de outro estágio qualitativo do conhecimento, isto é, "houve uma conversão qualitativa necessária no conceito seminal do campo e que fez o campo ser, existir" (E1). No caso das áreas citadas, o projeto seminal tem a ver com a matemática, com um grau de precisão e exatidão conceitual que não ocorre nas áreas da saúde e das humanas, cujas raízes conceituais de suas áreas são cânones culturalmente produzidos e constantemente variados e motivo de disputas políticas.

Com isso, o gestor afirma que, nas engenharias e exatas, existe uma relação de causalidade no cerne do conhecimento da área, ou seja, busca-se uma ciência preditiva, que visa identificar causa e efeito e não oferecer um prisma hermenêutico. Diferentemente, na saúde, por exemplo, o processo do diagnóstico é interpretativo, no direito, os códigos e normas são passíveis também de interpretações.

Essa característica seminal do campo de conhecimento das áreas duras faz com que elementos culturais e sociais não tenham espaço na sua formação, o que 
produz uma visão política determinada sobre as relações sociais e as ações institucionais. Ao compreender a dificuldade dessas áreas em reconhecer saberes de senso comum, não se está justificando eventuais posturas de descaso ou de preconceito para com estudantes cotistas ou pessoas cujos conhecimentos empíricos e argumentos utilizados não tenham legitimidade acadêmica.

Esse fato indica que, desenvolver a noção de reconhecimento como justiça (FRASER, 2001; 2007), ou seja, com ocupação de status similar entre todos os estudantes, as áreas precisam ser consideradas em suas especificidades. A formação pedagógica dos docentes precisa ser diferenciada de forma a produzir diálogo entre a estrutura do conhecimento e as concepções de aprendizagens e de requisitos indicados para acessar o conhecimento em cada um dos campos. A construção de uma cultura do reconhecimento passa pela renovação do modo como vemos o outro, como desenvolvemos os conteúdos e as atividades pedagógicas. Partir dos mesmos princípios didáticos que se trabalhava quando os alunos eram mais homogêneos é corroborar, em alguma medida, com a reprodução de injustiças socialmente acumuladas entre estudantes negros e alunos de baixa renda.

Consideramos que direito à educação pública de qualidade (CURY, 2008) não se materializa facilmente no caso brasileiro, sendo negado historicamente um conjunto de prerrogativas que garantiriam acesso e qualidade a segmentos sociais e indivíduos que têm permanecido a margem dos benefícios do desenvolvimento social e educacional no país. No ensino superior, também direito do cidadão, deve-se ter em conta que proporcioná-lo significa algo mais abrangente que a educação formal em si e envolve uma dimensão de oportunidade para o aprendizado efetivo, atendendo assim a uma dimensão de justiça.

Conforme Fraser (2001 e 2007), a promoção da justiça no mundo contemporâneo passa por dois movimentos básicos que não se excluem, a redistribuição e o reconhecimento. À medida que as ações afirmativas oferecem acesso, há uma redistribuição da educação como um bem social que implica em custos materiais. Por outro viés, cabe às universidades ofertarem a dimensão do reconhecimento, por meio da permanência e do sucesso acadêmico.

No quadro a seguir, reunimos os posicionamentos dos gestores entrevistados, a fim de que possamos ter uma visão sintética do material obtido, visualizando-o na relação com as categorias produzidas para a discussão. 
Quadro 1 - Percepção dos gestores em relação a categorias de atuação da universidade

\begin{tabular}{|c|c|c|}
\hline Variáveis & Excelência Acadêmica & Reconhecimento \\
\hline $\begin{array}{l}\text { Internacionalização } \\
\text { do conhecimento }\end{array}$ & $\begin{array}{l}\text { Gestores das áreas da comunicação, } \\
\text { engenharia e medicina deram priorida- } \\
\text { de a elementos ligados a internacio- } \\
\text { nalização e publicações com fator de } \\
\text { impacto. }\end{array}$ & $\begin{array}{l}\text { Gestores das áreas da educação, huma- } \\
\text { nidades e psicologia priorizaram a capa- } \\
\text { cidade de inserção no meio social local } \\
\text { e a capacidade de pesquisar e contribuir } \\
\text { para a solucionar problemas locais e na- } \\
\text { cionais. }\end{array}$ \\
\hline $\begin{array}{l}\text { Função social da uni- } \\
\text { versidade }\end{array}$ & $\begin{array}{l}\text { Gestores das áreas de medicina, da } \\
\text { comunicação e psicologia entendem } \\
\text { que função social está primordialmen- } \\
\text { te ligada às atividades de extensão ou } \\
\text { à qualidade das atividades estritamen- } \\
\text { te acadêmicas. }\end{array}$ & $\begin{array}{l}\text { Gestores das áreas de educação, huma- } \\
\text { nidades e engenharias consideraram que } \\
\text { a função social está na capacidade de re- } \\
\text { ceber e responder a demandas locais, no } \\
\text { vínculo com outros níveis educacionais. } \\
\text { Gestor da administração central concebe } \\
\text { as noções de excelência e de função so- } \\
\text { cial como antagônicas politicamente. }\end{array}$ \\
\hline $\begin{array}{l}\text { Relação entre sabe- } \\
\text { res acadêmicos e não } \\
\text { acadêmicos }\end{array}$ & $\begin{array}{l}\text { Gestores das áreas de engenharia e } \\
\text { comunicação avaliam que a relação } \\
\text { com saberes não acadêmicos está } \\
\text { obtendo mais atenção, mas entendem } \\
\text { que há desafios grandes para que isso } \\
\text { se consolide na universidade. }\end{array}$ & $\begin{array}{l}\text { Todos gestores salientaram que o poten- } \\
\text { cial de reconhecimento extra-acadêmico } \\
\text { depende da área do conhecimento. A } \\
\text { maioria enfatizou a necessidade de maior } \\
\text { interlocução entre tipos de conhecimen- } \\
\text { tos e de culturas distintas. }\end{array}$ \\
\hline
\end{tabular}

Fonte: elaborado pelos autores.

\section{Considerações finais}

Discutimos sobre desafios apresentados as universidades públicas brasileiras que trabalham com a perspectiva de excelência no cenário competitivo internacional e, ao mesmo tempo, precisam ser socialmente inclusivas e democráticas, isto é, promover o reconhecimento dos novos públicos da educação superior. Realizamos entrevistas com gestores acadêmicos que ocupam lugar privilegiado na arquitetura institucional de uma grande universidade federal do sul do Brasil.

Vimos que há perspectivas diferentes e até opostas sobre os temas indagados, de modo que as áreas de conhecimento nas quais os gestores atuam evidenciam concepções de ciência e de conhecimento acadêmico mais ou menos rígidos e mais ou menos capazes de visualizar a aprendizagem do estudante como um aspecto do trabalho acadêmico. Nesse sentido, há diferenças que se tornam disputas no interior da instituição de ensino superior. Há cargos estratégicos ocupados por pessoas críticas ao modelo tradicional de universidade, isso faz com que temas ligados à democratização e ao reconhecimento de grupos de estudantes sejam colocados em relevo. 
A categoria excelência foi tomada como um elemento norteador das atividades da universidade e, em geral, foi relacionada à pesquisa de ponta e à internacionalização. Alguns gestores propuseram ressignificar o que seja excelência na universidade, com o argumento de que não se poderia confundir excelência com elitismo acadêmico, elemento da tradição universitária no Brasil.

A materialização de uma cultura acadêmica do reconhecimento indicaria um processo de construção político, cultural, valorativo, de costumes, de mentalidades e de posturas capazes de contribuir para a superação de desigualdades, pensando em processos do campo acadêmico-educacional. Esse processo avançará com base nas condições de permanência dos estudantes, na existência de espaços de participação, na defesa de diferentes formas de aprendizagens e na afirmação dos sujeitos por meio da sua presença em espaços institucionalmente prestigiados.

Poucas instituições possuem potencial para desenvolver processos de reconhecimento sociocultural como as universidades. Elas têm capacidade para assumir papel importante no combate às desigualdades culturais, na valorização da diferença, no enfrentamento ao racismo, a preconceitos e intolerâncias. Essas instituições e seus sujeitos possuem ferramentas para fazê-lo, tais como os recursos intelectuais, estéticos e políticos que podem se constituir em força propulsora para mudanças. Para tanto, necessitam superar um conjunto de valores enraizados que foram herdados de uma sociedade desigual e elitista que criou a universidade no Brasil e que, por vezes, encontra refúgio em discursos que exaltam a excelência acadêmica e desconsideram outros temas importantes para a universidade pública.

\section{Notas}

1 No início dos anos oitenta, foi publicado por dois consultores chamados Tom Peters e Robert Waterman, um livro chamado "In Searche of excelence". Tornou-se um fenômeno de vendas e começou a servir como base para gestão empresarial e, ainda, passou a ser referência da defesa de que preceitos que funcionam na iniciativa privada poderiam ser adotados no setor público. PETERS, Thomas \& WATERMAN, Robert. In Search of Excellence: Lessons from America's Best Run Companies. New York: Harper\&Row, Pub. 1982.

2 Como exemplos de processos de formação continuada dos professores da educação básica relacionados as universidades públicas podemos citar, a partir de 2008, a elaboração pelo MEC (Ministério da Educação) e pela Capes (Coordenação de Aperfeiçoamento de Pessoal de Nível Superior) do Sistema Nacional Público de Formação dos Profissionais do Magistério. Diversos programas de formação continuada de profissionais de educação básica ligados ao FNDE (Fundo Nacional de Desenvolvimento da Educação) e a oferta de educação continuada a professores através de cursos semipresenciais da UAB (Universidade Aberta do Brasil) fizeram parte dessas ações.

3 Dados da "Taxa de abandono escolar precoce" medido pelo IBGE de 2010. Concebendo jovens de 18 a 24 anos que não haviam concluído o ensino médio e não estavam frequentando a escola. $\mathrm{O}$ abandono geral é de $36,50 \%$, mas entre os brancos, o total de abandono fica em 29,40\%, já entre os pretos e pardos tal abandono alcança 42,40\%, uma diferença significativa. Dado extraído de aplicativo da página do IBGE em: 4 out. 2018. http://www.ibge.gov.br/apps/snig/v1/?loc=0. 


\section{Referências}

ASHLEY, Patrícia Almeida. Ética e responsabilidade social nos negócios. São Paulo: Saraiva, 2001.

BOURDIEU, Pierre. Lê Sens Pratique. Paris: Minuit, 1980.

BOURDIEU, Pierre. Capital Cultural, Escuela y Espacio Social. México: Siglo Veinteuno, 1997.

BOURDIEU, Pierre; PASSERON, Jean-Claude. Os Herdeiros: os estudantes e a cultura. Trad. Ione Ribeiro Valle e Nilton Valle. Florianópolis: Editora da Ufsc, 2014.

CAMPOS, Luiz Augusto; FERES JUNIOR, João. Ação afirmativa, comunitarismo e multiculturalismo: relações necessárias ou contingentes?. Rev. bras. Ci. Soc., São Paulo, v. 29, n. 84, p. 103-118, fev. 2014.

CURY, Carlos Roberto Jamil. Sistema nacional de educação: desafio para uma educação igualitária e federativa. Educação e Sociedade. 2008, v. 29, n. 105, p. 1187-1209.

FRASER, Nancy. Da Redistribuição ao Reconhecimento? Dilemas da Justiça na Era Pós-Socialista. In: SOUZA, J. (Org.). Democracia hoje. Novos desafios para a teoria democrática contemporânea. Brasília, DF: UNB, 2001. p. 245-282.

FRASER, Nancy. Reconhecimento sem ética? Lua Nova, São Paulo, 70: 213-222, 2007.

GOERGEN, Pedro. Universidade e Compromisso Social. In: RISTOFF, D.; SEVEGNANI, P. (org.). Universidade e Compromisso social: Brasília, 25 e 26 de agosto de 2005. Brasília: Instituto Nacional de Estudos e Pesquisas Educacionais Anísio Teixeira, 2006. p. 65-95. (Coleção Educação Superior em Debate; v. 4).

HOOD, Christopher. A Public Management for All Seasons? Public Administration. 69 (1), 3-19. 1991.

HONNETH, Axel. Luta por reconhecimento: a gramática moral dos conflitos sociais. Trad. de Luiz Repa. São Paulo: Ed. 34, 2003.

KAWASAKI, Clarice Sumi. Universidades públicas e sociedades: uma parceria necessária. Revista da Faculdade de Educação. São Paulo, vol. 23, n.1-2, Jan 1997.

LYOTARD, Jean-François. A Condição pós-moderna. 8 ed. Rio de Janeiro: Jose Olympio, 2004.

MARGINSON, Simon. University rankings, government and social order: managing the field of higher education according to the logic of the performative present-as-future. In: SIMONS, M.; OLSSEN, M; PETERS, M. (Ed.). Re-reading education policies: a handbook studying the policy agenda of the 21st century. Rotterdam: Sense Publishers, 2009.

POLLITT, Christopher. Managerialism and the Public Services: Cuts or cultural change in the 1990s? 2. ed., Oxford: Blackwell Business, 1993.

READINGS, Bill. A universidade em ruínas. Coimbra, Angelus Novus, 2003.

SOBRINHO, José Dias. Educação Superior: bem público, equidade e democratização. Avaliação, Campinas; Sorocaba, SP, v. 18, n. 1, p. 107-126, mar. 2013. 
TAYLOR, Charles. et al. Multiculturalismo. Lisboa: Instituto Piaget, 1994.

TROW, Martin. Reflections on the Transition from Elite to Mass to Universal Access: Forms and Phases of Higher Education in Modern Societies since WWII. 2005. Disponível em: http://repositories.cdlib.org/igs/WP2005-4. Acesso em: out. 2018. 